Article

\title{
Four Different Carotid Atherosclerotic Behaviors Based on Luminal Stenosis and Plaque Characteristics in Symptomatic Patients: An in Vivo Study
}

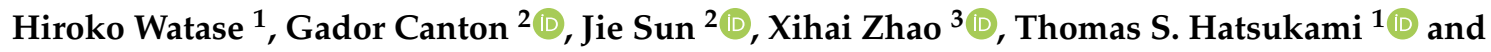 \\ Chun Yuan $2, *,+$ \\ 1 Department of Surgery, University of Washington, United States 850 Republican Street, Seattle, WA 98109, \\ USA; hiroko7@uw.edu (H.W.); tomhat@uw.edu (T.S.H.) \\ 2 Department of Radiology, University of Washington, United States 850 Republican Street, Seattle, WA 98109, \\ USA; gcanton@uw.edu (G.C.); sunjie@uw.edu (J.S.) \\ 3 Center for Biomedical Imaging Research, Department of Biomedical Engineering, Tsinghua University \\ School of Medicine, China Haidian District, Beijing 100084, China; xihaizhao@tsinghua.edu.cn \\ * Correspondence: cyuan@uw.edu; Tel.: +206-616-9346 \\ + On behalf of the CARE-II Study Collaborators.
}

Received: 10 September 2019; Accepted: 30 September 2019; Published: 2 October 2019

\begin{abstract}
Correct stratification of ischemic stroke risk allows for the proper treatment of carotid atherosclerotic disease. We seek to differentiate plaque types based on stenosis level and plaque morphology. The Chinese Atherosclerosis Risk Evaluation (CARE-II) study is a cross-sectional, observational, multicenter study to assess carotid atherosclerotic plaques in symptomatic subjects using vessel wall magnetic resonance imaging. Plaque morphology and presence of plaque components were reviewed using multi-contrast magnetic resonance imaging. The carotid arteries were divided into four groups based on stenosis level and plaque components. Out of 1072 ischemic stroke subjects, 452 ipsilateral side carotid arteries were included. Significant stenosis (SS) ( $\geq 50 \%$ stenosis) with high-risk plaque (HRP) features was present in 37 arteries $(8.2 \%), \mathrm{SS}(+) / \mathrm{HRP}(-)$ in 29 arteries $(6.4 \%), \mathrm{SS}(-) / \mathrm{HRP}(+)$ in 57 arteries $(12.6 \%)$, and SS(-)/HRP(-) in 329 arteries $(72.8 \%)$. The prevalence of SS(-)/HRP $(+)$ arteries in this cohort was substantial and had greater wall thickness than the SS(+)/HRP(-) group. These arteries may be misclassified for carotid revascularization by current guidelines based on the degree of luminal stenosis only. These findings have implications for further studies to assess stroke risk using vessel wall imaging.
\end{abstract}

Keywords: vessel wall magnetic resonance imaging; carotid atherosclerotic plaque; high-risk plaque; carotid stenosis

\section{Introduction}

Approximately $15-20 \%$ of ischemic strokes derive from carotid atherosclerotic plaques [1]. Currently, the most widely used estimator of ischemic stroke risk in both symptomatic and asymptomatic patients is the degree of carotid stenosis [2-5]. Rupture of atherosclerotic plaque in the carotid artery is believed to be the main source of ischemic embolic cerebrovascular events, including stroke and transient ischemic attacks [6]. This has led to many ground-breaking studies that link plaque rupture to compositional features. The ability of magnetic resonance imaging (MRI) to characterize plaque components is now well established and multiple MRI based prospective studies have identified the plaque features linked to the development of future clinical events. These features have been defined as: plaques with thinned or ruptured fibrous cap, presence of intraplaque hemorrhage (IPH), and presence of a large lipid-rich necrotic core (LRNC) [7-14]. Thus, the presence of these features in MRI 
may be considered as indicators of high-risk plaque (HRP) for ischemic stroke. Several studies have also indicated that measurement of stenosis alone underestimates plaque burden $[15,16]$. Further evidence of the discrepancies between stenosis and stroke risk are found in studies examining patients diagnosed with cryptogenic strokes, which found plaques with HRP features in carotid arteries with $<50 \%$ stenosis $[17,18]$. These findings suggest that there may be carotid-related strokes that are missed due to risk assessments based on stenosis levels [17-21]. In the CARE-II (Chinese Atherosclerosis Risk Evaluation) study, 1072 ischemic stroke subjects with evidence of carotid atherosclerotic plaques underwent MRI scans of the carotid arteries [22,23]. The current study examines the relationships between plaque morphology, stenosis levels, and location of plaques in the ipsilateral side of carotid arteries to identify groups whose risk may be miscategorized by current guidelines [2-5].

\section{Materials and Methods}

\subsection{Subject Enrollment}

This is a cross-sectional study from the CARE-II study data (NCT02017756). The overall design and objectives of CARE-II have been published [22,23]. In brief, CARE-II is an observational, multicenter study to assess carotid atherosclerotic plaque using standardized carotid MRI in a Chinese population. Inclusion criteria were: (1) 18-80 years of age; (2) history of anterior circulation (carotid territory) cerebral hemispheric ischemic symptoms or amaurosis fugax, including ischemic stroke and transient ischemia attack in the previous 14 days; and (3) atherosclerotic plaque in at least one carotid artery, as determined by B-mode ultrasound (intima-media thickness $\geq 1.5 \mathrm{~mm}$ ). Exclusion criteria were: (1) evidence of cardioembolic stroke; (2) hemorrhagic stroke; (3) history of radiation therapy in the neck; (4) claustrophobia; and (5) contraindication to MR imaging. Clinical characteristics from the time of the hospital visit for the recent ischemic symptoms were acquired from medical records. History of hypertension (defined as diastolic blood pressure $\geq 90 \mathrm{~mm} \mathrm{Hg}$ or systolic blood pressure $\geq 140 \mathrm{~mm} \mathrm{Hg}$ ), hyperlipidemia (defined as elevated concentrations of any or all of the lipids in the plasma, such as low density lipoprotein $>140 \mathrm{mg} / \mathrm{dL}$, total cholesterol $>200 \mathrm{mg} / \mathrm{dL}$, or triglycerides $>50 \mathrm{mg} / \mathrm{dL}$ ), diabetes mellitus (fasting blood sugar level $\geq 126 \mathrm{mg} / \mathrm{dL}$, 2-hour oral glucose tolerance test result $\geq 200 \mathrm{mg} / \mathrm{dL}$, or hemoglobin A1c $\geq 6.5 \%$ ), smoking (current or former), statin use, and coronary heart disease (myocardial infarction or angina) was collected. Institutional review board approvals were obtained for the entire study and from each participating institution, and all study participants provided written informed consent prior to enrollment.

\subsection{Magnetic Resonance (MR) Imaging}

Participating radiologists and MR technologists from each imaging site were trained on carotid MRI acquisition and quality evaluation. A standardized carotid MR imaging protocol was implemented for carotid plaque imaging at all 13 participating centers. All carotid MR imaging was performed on 3.0 T MR scanners with dedicated 8-channel phase-array carotid coils.

\subsection{Image Analysis}

Two experienced reviewers who were blinded to the demographic and clinical information analyzed the bilateral carotid artery images with consensus. Image quality was rated per artery on a four-point scale $(1=$ poor, $4=$ excellent). Images with an image quality rating of less than 2 were excluded from this study. Different contrast weighted images were registered during image review using the carotid bifurcation as a reference. Arteries without a carotid bifurcation within the field-of-view were excluded. Lumen and outer wall boundaries were outlined manually on all axial images in $16 \mathrm{~mm}$ coverage ( $8 \mathrm{~mm}$ distal and proximal to bifurcation) using CASCADE, a custom-designed image analysis software package (University of Washington, Seattle, WA, USA) [24]. The presence/absence and areas of plaque components, including LRNC, calcification, IPH, and luminal surface disruption (fibrous cap rupture or ulceration) were identified and measured using published 
criteria $[25,26]$. HRP was defined as presence of IPH, large LRNC (occupying more than $40 \%$ of the wall area), or luminal surface disruption. The minimum lumen area, maximum total vessel area, maximum wall thickness, and eccentricity index at the greatest maximum wall thickness level in the ipsilateral side to ischemic symptoms were analyzed. Eccentricity index was calculated in the axial image per slice: (maximum wall thickness-minimum wall thickness)/maximum wall thickness [27,28]. Three-dimensional time-of-flight MR angiographic images were used to measure carotid stenosis using the NASCET criteria [29]. This analysis was performed independently of carotid plaque morphology and composition measurements. Arteries were classified into four groups (Figure 1): significant $(\geq 50 \%)$ stenosis (SS) $(+) / \mathrm{HRP}(+): \geq 50 \%$ stenosis and presence of HRP; SS(+)/HRP(-): $\geq 50 \%$ stenosis and absence of HRP; SS(-)/HRP(+): $<50 \%$ stenosis and presence of HRP; and SS(-)/HRP(-): $<50 \%$ stenosis and absence of HRP.
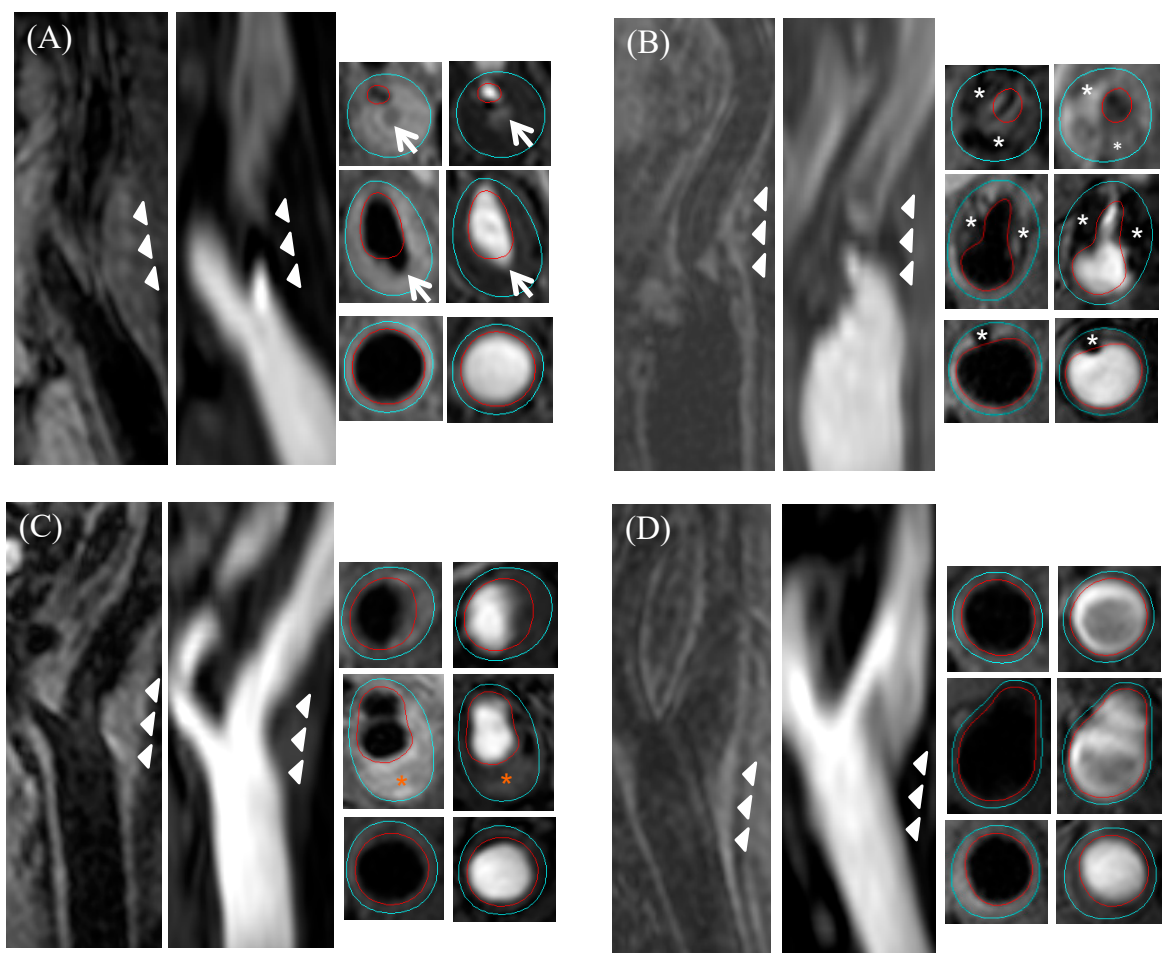

Figure 1. Example magnetic resonance images of the four groups. (A) $\mathrm{SS}(+) / \mathrm{HRP}(+)$ : significant stenosis with ulceration (white arrow); (B) SS(+)/HRP(-): significant stenosis with calcified plaque (white asterisk); (C) SS(-)/HRP(+): no significant stenosis with IPH (orange asterisk); (D) SS(-)/HRP (-): no significant stenosis with small plaque. Red outline, lumen; light blue outline, outer vessel wall; white arrowheads, outer vessel wall. (SS = significant stenosis, HRP = high-risk plague, IPH = intraplaque hemorrhage).

\subsection{Statistical Analysis}

The summary statistics of the data are presented as mean with standard deviation for continuous variables and count with percentage for binary variables. Clinical and carotid plaque morphology were compared between the HRP $(+)$ and HRP (-) groups using the Mann-Whitney U test (continuous variables) or Fisher's exact test (binary variables). Univariate and multivariate linear (continuous variables) and logistic (binary variables) regression analyses were performed to assess the differences in carotid plaque morphology between HRP (+) and HRP (-) arteries after accounting for differences in clinical risk factors. Sex is an important factor for atherosclerotic carotid disease [30,31]. Although no significant difference was found, sex was included in the multivariate analysis for the both stenosis groups. In addition, age, hypertension and low density lipoprotein cholesterol (LDL) level were adjusted in the significant stenosis group, and age, smoking, and diabetes mellitus were in the 
non-significant stenosis group. Although height also showed a significant difference between the two arteries in the significant stenosis group, it is strongly associated with sex. Therefore, height was not included in the multivariate analysis. Throughout the analysis, a two-sided $p$-value $(p)<0.05$ was considered statistically significant without adjustment for the number of comparisons for this initial hypothesis-generating study. All data analyses were preformed using STATA/SE version 15.1 software (StataCorp; College Station, TX, USA).

\section{Results}

\subsection{Clinical Characteristics}

Of the 1072 recruited subjects, 1047 subjects had bilateral carotid vessel wall MRI with sufficient image quality, of whom 595 subjects were excluded because of missing ischemic symptom side information or time-of-flight image, or insufficient coverage on vessel wall MRI. Among the 452 ipsilateral arteries, $37(8.2 \%)$ arteries were in SS(+)/HRP(+), $29(6.4 \%)$ arteries in SS(+)/HRP(-), $57(12.6 \%)$ arteries in SS(-)/HRP(+), and $329(72.8 \%)$ arteries in SS(-)/HRP(-). Demographic and clinical characteristics of this study population are included in Table 1. Subjects with HRP were older and greater height and LDL level with a higher prevalence of history of hypertension in the SS (+) groups, and older, smoking, and diabetes in the SS(-) groups as compared to those without HRP. Although no significant difference was found, males tended to have HRP compared to females in both significant and non-significant stenosis groups.

Table 1. Clinical characteristics of 452 subjects.

\begin{tabular}{|c|c|c|c|c|c|c|}
\hline & \multicolumn{3}{|c|}{ SS (+) } & \multicolumn{3}{|c|}{ SS (-) } \\
\hline & $\begin{array}{c}\text { HRP(+) } \\
(37)\end{array}$ & $\begin{array}{l}\text { HRP (-) } \\
\text { (29) }\end{array}$ & $p$-value & $\begin{array}{c}\text { HRP (+) } \\
\text { (57) }\end{array}$ & $\begin{array}{l}\text { HRP (-) } \\
\text { (329) }\end{array}$ & $p$-value \\
\hline Age, $y$ & $66.1 \pm 8.4$ & $56.4 \pm 11.8$ & $<0.001$ & $63.7 \pm 9.2$ & $61.0 \pm 10.3$ & 0.04 \\
\hline Sex, male & $33(89.2)$ & $20(69.0)$ & 0.06 & $45(79.0)$ & $219(66.6)$ & 0.07 \\
\hline BMI, $\mathrm{kg} / \mathrm{m}^{2}$ & $25.4 \pm 2.6$ & $24.4 \pm 2.7$ & 0.19 & $24.8 \pm 3$ & $24.7 \pm 3.1$ & 0.64 \\
\hline Height, $\mathrm{cm}$ & $168.8 \pm 4.9$ & $166.1 \pm 5.9$ & 0.03 & $167.8 \pm 6.4$ & $166.8 \pm 7.5$ & 0.41 \\
\hline Smoking & $28(75.7)$ & $17(58.6)$ & 0.19 & $38(66.7)$ & $149(45.3)$ & 0.004 \\
\hline Hypertension & $33(89.2)$ & $19(65.5)$ & 0.03 & $45(79.0)$ & $243(73.9)$ & 0.51 \\
\hline Hyperlipidemia & $24(64.9)$ & $17(58.6)$ & 0.62 & $37(64.9)$ & $188(57.1)$ & 0.31 \\
\hline LDL, mg/dl & $123.0 \pm 36.7$ & $106.6 \pm 33.5$ & 0.04 & $116.7 \pm 38.2$ & $114.2 \pm 38.3$ & 0.64 \\
\hline $\mathrm{HDL}, \mathrm{mg} / \mathrm{dl}$ & $42.2 \pm 8.9$ & $44.2 \pm 12.8$ & 0.79 & $41.2 \pm 9.8$ & $44.3 \pm 19.5$ & 0.21 \\
\hline $\mathrm{TC}, \mathrm{mg} / \mathrm{dl}$ & $183.1 \pm 47.4$ & $178.7 \pm 41.1$ & 0.54 & $183.0 \pm 42.2$ & $181.2 \pm 43.9$ & 0.79 \\
\hline $\mathrm{TG}, \mathrm{mg} / \mathrm{dl}$ & $174.8 \pm 110.1$ & $144.1 \pm 72.3$ & 0.37 & $169.0 \pm 79.0$ & $158.3 \pm 90.5$ & 0.14 \\
\hline Diabetes mellitus & $13(35.1)$ & $9(31.0)$ & 0.80 & $24(42.1)$ & $92(28.0)$ & 0.04 \\
\hline $\begin{array}{l}\text { Coronary heart } \\
\text { disease }\end{array}$ & $10(27.0)$ & $6(20.7)$ & 0.59 & $9(15.8)$ & 45 (13.7) & 0.68 \\
\hline On statin & $21(56.8)$ & $12(41.4)$ & 0.32 & $30(52.6)$ & $138(42.0)$ & 0.15 \\
\hline
\end{tabular}

Values are mean \pm SD or $n(\%)$. Significant difference $(p<0.05)$ is marked in bold face. SD, standard deviation; BMI, body mass index; LDL, low density lipoprotein cholesterol; HDL, high density lipoprotein cholesterol; TC, total cholesterol; TG, triglyceride; SS, significant stenosis, HRP, high-risk plaque.

\subsection{Comparison of Plaque Morphology}

Tables 2 and 3 summarizes the plaque morphological features between HRP (+) and HRP (-) arteries in the SS (+) and SS (-) groups, respectively. In both SS(+) and SS(-) groups, HRP(+) arteries had a smaller lumen area, greater wall thickness, and eccentricity index compared to the HRP(-) group (all $p<0.05$ ) before and after adjusting clinical factors. As shown in Figure 2, these measurements in each group were significantly different. SS(+)/HRP(+) had the smallest lumen, greatest wall thickness, and eccentricity index. Minimum lumen areas in SS(+)/HRP(-) were significantly smaller than in $\mathrm{SS}(-) / \mathrm{HRP}(+)\left(14.7 \pm 9.7 \mathrm{~mm}^{2}\right.$ vs. $\left.25.4 \pm 11.6 \mathrm{~mm}^{2}, p<0.001\right)$, but wall thickness was thinner $(3.0 \pm 1.4 \mathrm{~mm}$ vs. $4.5 \pm 1.5 \mathrm{~mm}, p<0.001)$. In addition, total vessel areas in SS(+)/HRP(-) were significantly smaller, compared to the other three groups. 
Table 2. Comparison plaque morphology between high-risk plaque (HRP) (+) and (-) arteries.

\begin{tabular}{|c|c|c|c|c|c|c|}
\hline & & & \multicolumn{2}{|c|}{ Univariate } & \multicolumn{2}{|c|}{ Multivariate } \\
\hline & & & $\beta$ or Odds ratio $(95 \% \mathrm{CI})$ & $p$-Value & $\beta$ or Odds ratio $(95 \% \mathrm{CI})$ & $p$-Value \\
\hline Significant stenosis group & $\begin{array}{c}\text { HRP (+) } \\
(37)\end{array}$ & $\begin{array}{c}\text { HRP (-) } \\
\text { (29) }\end{array}$ & & & & \\
\hline Minimum lumen area, $\mathrm{mm}^{2}$ & $9.4 \pm 6.2$ & $14.7 \pm 9.7$ & $-5.2(-9.2,-1.3)$ & 0.01 & $-5.4(-10.0,-0.8)$ & 0.02 \\
\hline Maximum total vessel area, $\mathrm{mm}^{2}$ & $128.6 \pm 39.9$ & $101.3 \pm 27.0$ & $27.3(10.0,44.5)$ & 0.002 & $26.2(7.1,45.3)$ & 0.008 \\
\hline Maximum wall thickness, $\mathrm{mm}$ & $5.8 \pm 1.6$ & $3.0 \pm 1.4$ & $2.8(2.0,3.5)$ & $<0.001$ & $2.5(1.6,3.4)$ & $<0.001$ \\
\hline Eccentricity index & $0.8 \pm 0.1$ & $0.6 \pm 0.2$ & $0.2(0.1,0.2)$ & $<0.001$ & $0.2(0.1,0.2)$ & $<0.001$ \\
\hline No significant stenosis group & $\begin{array}{c}\text { HRP (+) } \\
(57)\end{array}$ & $\begin{array}{c}\text { HRP (-) } \\
(329)\end{array}$ & & & & \\
\hline Minimum lumen area, $\mathrm{mm}^{2}$ & $25.4 \pm 11.6$ & $31.9 \pm 10.7$ & $-6.5(-9.6,-3.5)$ & $<0.001$ & $-6.9(-10.0,-3.9)$ & $<0.001$ \\
\hline Maximum total vessel area, $\mathrm{mm}^{2}$ & $140.6 \pm 39.0$ & $130.5 \pm 36.4$ & $10.2(-0.2,20.5)$ & 0.055 & $6.9(-3.2,17.0)$ & 0.18 \\
\hline Maximum wall thickness, mm & $4.5 \pm 1.5$ & $2.2 \pm 1.0$ & $2.3(2.0,2.6)$ & $<0.001$ & $2.2(1.9,2.5)$ & $<0.001$ \\
\hline Eccentricity index & $0.8 \pm 0.1$ & $0.5 \pm 0.2$ & $0.2(0.2,0.3)$ & $<0.001$ & $0.2(0.2,0.3)$ & $<0.001$ \\
\hline
\end{tabular}

Values are mean $\pm \mathrm{SD}, n(\%)$ or median (IQR). Significant difference $(p<0.05)$ is marked in bold face. HRP, high-risk plaque; LRNC, lipid-rich necrotic core; SD, standard deviation; $\mathrm{IQR}$, interquartile range. 


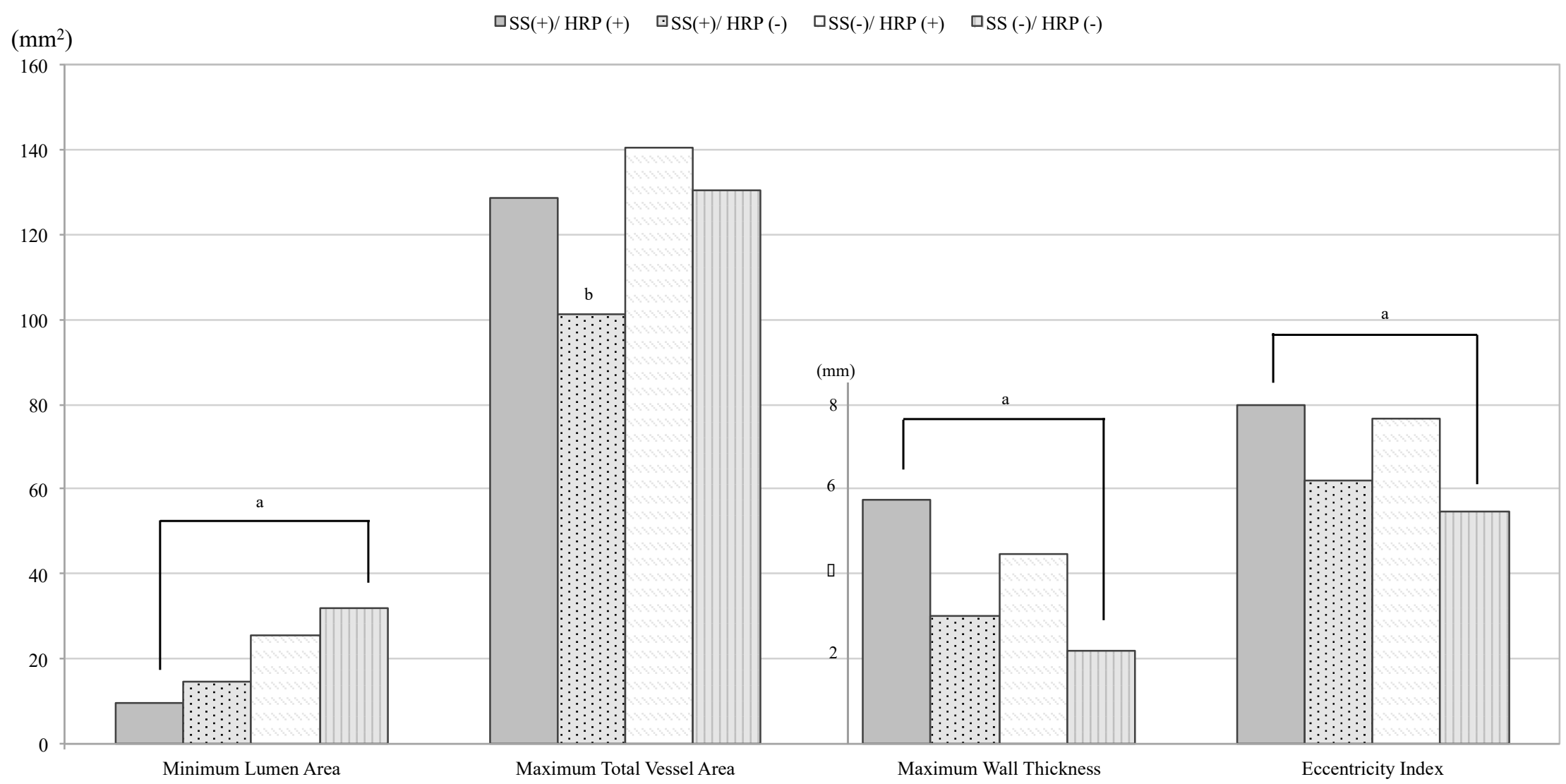

Figure 2. Comparison of plaque morphology between the four groups. ${ }^{a}$ Values were significant different with each other ${ }^{b}$ Only ss $(+) / \mathrm{HRP}(-)$ group was significant different from the other three groups. 


\subsection{Comparison of Location of Maximum Wall Thickness}

When location of plaque was compared between SS(+) and SS(-) arteries and about $60 \%$ of SS(+) arteries had plaque in the internal carotid (ICA) segment, whereas about $80 \%$ of SS(-) artery had plaque in the common carotid (CCA) segment $(p<0.001)$ (Table 3$)$.

Table 3. Comparison location of plaque.

\begin{tabular}{cccc}
\hline & $\begin{array}{c}\text { Significant Stenosis } \\
(\mathbf{S S})(+)(\mathbf{6 6})\end{array}$ & $\begin{array}{c}\text { SS (-) } \\
\mathbf{( 3 8 6 )}\end{array}$ & $p$-Value \\
\hline Internal carotid (ICA) segment & $39(59.1)$ & $78(20.2)$ & $<0.001$ \\
Common carotid (CCA) segment & $27(40.9)$ & $308(79.8)$ & \\
\hline & Values are $n(\%)$. &
\end{tabular}

\section{Discussion}

In this study, we sought to determine the differences between the degree of stenosis and presence of HRP in the carotid artery ipsilateral to a recent anterior circulation ischemic cerebrovascular event using MR plaque imaging. The arteries were classified into the four groups based on luminal stenosis, as currently used in clinical practice, and HRP status. Examining the plaque morphology (lumen area, total vessel area, wall thickness, and eccentricity index) within the four groups (Table 2 and Figure 2), an interesting trend emerges. Vessel wall measurements, including wall thickness and eccentricity index, followed a clear descending trend: $\mathrm{SS}(+) / \mathrm{HRP}(+), \mathrm{SS}(-) / \mathrm{HRP}(+), \mathrm{SS}(+) / \mathrm{HRP}(-)$, and SS(-)/HRP(-). However, lumen area did not follow this trend. This difference strongly suggests the need for a new way of assessing the severity of atherosclerosis through not only the stenosis level but also the vessel wall measurements (i.e., wall thickness). This confirms a previous report based on the same data set, where the authors argue that wall thickness measurement is a better predictor of HRP than the degree of stenosis [23].

The SS(+)/HRP(-) arteries represent about $6 \%$ of the total cohort. Although current guidelines suggest carotid revascularization in $\geq 50 \%$ stenosis of symptomatic patients, vessel wall MRI in the SS(+)/HRP(-) group showed mild wall thickness and smallest total vessel area (Table 2 and Figure 2). Notably, this group showed mostly negative remodeling with significantly small total vessel area. In addition, Hosseini et al. has reported that 179 symptomatic patients with $\geq 50 \%$ carotid stenosis and absence of IPH had an estimated annual absolute stroke risk of only $0.6 \%$ [7]. Further studies are needed to determine if the arteries in the SS(+)/HRP(-) group (significant luminal stenosis and absence of HRP) are better served with medical management rather than carotid revascularization.

$\mathrm{SS}(-) / \mathrm{HRP}(+)$ arteries were identified in a relatively large number $(13 \%)$ of the total cohort. Wall thickness and eccentricity indexes in this group were significantly larger than in the SS(+)/HRP(-) group, whereas lumen areas did not indicate severe stenosis. Thus, increasing wall thickness resulting in outer vessel wall expansion may lead to eccentric plaques. This phenomenon suggests that positive remodeling accounted for the absence of significant luminal stenosis despite increasing wall thickness. Although this group is now categorized as not needing surgical intervention by current clinical guidelines, this group may represent a higher risk group based on vessel wall MRI. Carotid arteries in patients with embolic stroke of undetermined source could plausibly belong to this SS(-)/HRP(+) group $[17,18,20]$. Further investigation into the risk profiles for this group are needed to develop predictive models that incorporate clinical and hemodynamic data.

Systemic factors including older age, smoking, hypertension, and diabetes were associated with presence of HRP (Table 1), which had been previously reported in symptomatic and asymptomatic patients with mild to severe stenosis [30,32-34]. Thus, when HRP was present in the ipsilateral side artery, the contralateral side artery was more likely to have HRP, compared to those without HRP in the ipsilateral side artery (odds ratio 5.4 [95\% confidence interval: 2.8-10.3], $p<0.001$ ) (not shown in the table). When the location of plaque was compared between SS(+) and SS(-) arteries, SS(+) arteries more 
commonly had plaque in the ICA segment and more SS(-) arteries had plaque in the CCA segment $(p<0.001)$ (Table 3). This result might indicate that the CCA segment underwent positive remodeling, whereas the ICA segment demonstrated negative remodeling behaviors, which are consistent with previous reports [35-38]. The location of plaque varied between and within individuals [39] and might be influenced by hemodynamic conditions or carotid bifurcation anatomy, including absolute vessel size, diameter, and area ratios in the CCA, ICA, and external carotid artery $[40,41]$. Therefore, presence of HRP might be influenced by systematic risk factors, and presence of SS might be influenced by location of plaque and local geometric factors.

This study has several limitations. First, ischemic stroke might not always be secondary to large-artery atherosclerosis [42]. In the future, the ipsilateral carotid arteries in subjects with ischemic stroke due to large artery atherosclerosis only should be analyzed based on this four-group ranking. Second, carotid arteries with $16 \mathrm{~mm}$ coverage ( $8 \mathrm{~mm}$ distal and proximal to bifurcation) were included in this sub-analysis study. Plaques outside of this coverage may be missed, but the same range for all carotid arteries was analyzed to compare the vessel morphology. If we change the inclusion criteria to $2 \mathrm{~cm}$ coverage, no HRP (+) arteries will be added and the total sample size will be decreased by $14 \%$. We think that $16 \mathrm{~mm}$ coverage ( $8 \mathrm{~mm}$ distal and proximal to the bifurcation) is suitable to test the hypothesis in this study, but large coverage 3D imaging techniques that have been recently developed could be more suitable for clinical applications $[43,44]$. Third, the measurement of luminal stenosis was based on angiographic images derived from a three-dimensional time-of-flight imaging sequence. MR angiography may overestimate carotid artery stenosis compared to digital subtraction angiography, which is the gold standard for measuring carotid artery stenosis. Fourth, the results of this study should be interpreted cautiously because $p$-values were not adjusted for number of comparisons. Therefore, this analysis should be considered hypothesis generating. Lastly, this is a cross-sectional study; thus, it lacks data on the role of HRP features and luminal stenosis in plaque progression and their changes over time. Prospective studies are needed to properly stratify stroke risk using this four-group ranking, especially in $\mathrm{SS}(+) / \mathrm{HRP}(-)$ and $\mathrm{SS}(-) / \mathrm{HRP}(+)$ groups.

\section{Conclusions}

By comprehensive evaluation of carotid vessel lumen and wall size and assessing the presence of HRP features in a cohort of subjects with anterior circulation ischemic cerebrovascular symptoms, we found that carotid arteries $\geq 50 \%$ or $<50 \%$ can be further divided into those with and without HRP. The prevalence of SS(-)/HRP(+) arteries in this cohort was substantial and had greater wall thickness than the SS(+)/HRP(-) group. Presence of HRP was associated with clinical risk factors such as older age, male sex, smoking, and diabetes, whereas stenosis level appears to be influenced by the location of plaque. Further prospective studies are needed to validate these findings and stratify future stroke risk in these four groups.

Author Contributions: Conceptualization, H.W., X.Z., T.S.H. and C.Y.; methodology, G.C. and J.S.; formal analysis, H.W.; writing—original draft preparation, H.W.; writing—review and editing, G.C., J.S., T.S.H. and C.Y.; supervision, C.Y.

Funding: This study was supported by the National Natural Science Foundation of China (83161120402). Philips Healthcare provided assistance in training and implementation of MRI techniques. J.S. received support from the American Heart Association (17MCPRP33671077).

Acknowledgments: Philips Healthcare provided assistance in training and implementation of MRI techniques. Zach Miller and Hardik Maini from the University of Washington provided language editing for this article. We thank the other investigators, the staff, and the participants of the CARE-II study (Chinese Atherosclerosis Risk Evaluation, NCT02017756) for their valuable contributions. A full list of participating CARE-II investigators and institutions can be found at https://clinicaltrials.gov/ct2/show/NCT02017756.

Conflicts of Interest: T.S.H. and C.Y. received research grants from Philips Healthcare. All other authors have no conflict of interest to disclose. The funders had no role in the design of the study; in the collection, analyses, or interpretation of data; in the writing of the manuscript, or in the decision to publish the results". 


\section{References}

1. Chaturvedi, S.; Bruno, A.; Feasby, T.; Holloway, R.; Benavente, O.; Cohen, S.N.; Cote, R.; Hess, D.; Saver, J.; Spence, J.D.; et al. Carotid endarterectomy-an evidence-based review: report of the Therapeutics and Technology Assessment Subcommittee of the American Academy of Neurology. Neurology 2005, 65, $794-801$. [CrossRef] [PubMed]

2. Brott, T.G.; Halperin, J.L.; Abbara, S.; Bacharach, J.M.; Barr, J.D.; Bush, R.L.; Cates, C.U.; Creager, M.A.; Fowler, S.B.; Friday, G.; et al. 2011 ASA/ACCF/AHA/AANN/AANS/ACR/ASNR/CNS/SAIP/SCAI/SIR/SNIS/ SVM/SVS guideline on the management of patients with extracranial carotid and vertebral artery disease: Executive summary: a report of the American College of Cardiology Foundation/American Heart Association Task Force on Practice Guidelines, and the American Stroke Association, American Association of Neuroscience Nurses, American Association of Neurological Surgeons, American College of Radiology, American Society of Neuroradiology, Congress of Neurological Surgeons, Society of Atherosclerosis Imaging and Prevention, Society for Cardiovascular Angiography and Interventions, Society of Interventional Radiology, Society of NeuroInterventional Surgery, Society for Vascular Medicine, and Society for Vascular Surgery. J. Am. Coll Cardiol. 2011, 57, 1002-1044. [CrossRef] [PubMed]

3. Kernan, W.N.; Ovbiagele, B.; Black, H.R.; Bravata, D.M.; Chimowitz, M.I.; Ezekowitz, M.D.; Fang, M.C.; Fisher, M.; Furie, K.L.; Heck, D.V.; et al. Guidelines for the prevention of stroke in patients with stroke and transient ischemic attack: a guideline for healthcare professionals from the American Heart Association/American Stroke Association. Stroke 2014, 45, 2160-2236. [CrossRef] [PubMed]

4. Meschia, J.F.; Bushnell, C.; Boden-Albala, B.; Braun, L.T.; Bravata, D.M.; Chaturvedi, S.; Creager, M.A.; Eckel, R.H.; Elkind, M.S.; Fornage, M.; et al. Guidelines for the primary prevention of stroke: a statement for healthcare professionals from the American Heart Association/American Stroke Association. Stroke 2014, 45, 3754-3832. [CrossRef]

5. Abbott, A.L.; Paraskevas, K.I.; Kakkos, S.K.; Golledge, J.; Eckstein, H.H.; Diaz-Sandoval, L.J.; Cao, L.; Fu, Q.; Wijeratne, T.; Leung, T.W.; et al. Systematic Review of Guidelines for the Management of Asymptomatic and Symptomatic Carotid Stenosis. Stroke 2015, 46, 3288-3301. [CrossRef]

6. Naghavi, M.; Libby, P.; Falk, E.; Casscells, S.W.; Litovsky, S.; Rumberger, J.; Badimon, J.J.; Stefanadis, C.; Moreno, P.; Pasterkamp, G.; et al. From vulnerable plaque to vulnerable patient: a call for new definitions and risk assessment strategies: Part I. Circulation 2003, 108, 1664-1672. [CrossRef]

7. Hosseini, A.A.; Kandiyil, N.; Macsweeney, S.T.; Altaf, N.; Auer, D.P. Carotid plaque hemorrhage on magnetic resonance imaging strongly predicts recurrent ischemia and stroke. Ann. Neurol. 2013, 73, 774-784. [CrossRef]

8. Takaya, N.; Yuan, C.; Chu, B.; Saam, T.; Underhill, H.; Cai, J.; Tran, N.; Polissar, N.L.; Isaac, C.; Ferguson, M.S.; et al. Association between carotid plaque characteristics and subsequent ischemic cerebrovascular events: a prospective assessment with MRI-initial results. Stroke 2006, 37, 818-823. [CrossRef]

9. Sadat, U.; Weerakkody, R.A.; Bowden, D.J.; Young, V.E.; Graves, M.J.; Li, Z.Y.; Tang, T.Y.; Gaunt, M.E.; Hayes, P.D.; Gillard, J.H. Utility of high resolution MR imaging to assess carotid plaque morphology: a comparison of acute symptomatic, recently symptomatic and asymptomatic patients with carotid artery disease. Atherosclerosis 2009, 207, 434-439. [CrossRef]

10. Saam, T.; Cai, J.; Ma, L.; Cai, Y.Q.; Ferguson, M.S.; Polissar, N.L.; Hatsukami, T.S.; Yuan, C. Comparison of symptomatic and asymptomatic atherosclerotic carotid plaque features with in vivo MR imaging. Radiology 2006, 240, 464-472. [CrossRef]

11. Yuan, C.; Zhang, S.X.; Polissar, N.L.; Echelard, D.; Ortiz, G.; Davis, J.W.; Ellington, E.; Ferguson, M.S.; Hatsukami, T.S. Identification of fibrous cap rupture with magnetic resonance imaging is highly associated with recent transient ischemic attack or stroke. Circulation 2002, 105, 181-185. [CrossRef] [PubMed]

12. Xu, D.; Hippe, D.S.; Underhill, H.R.; Oikawa-Wakayama, M.; Dong, L.; Yamada, K.; Yuan, C.; Hatsukami, T.S. Prediction of high-risk plaque development and plaque progression with the carotid atherosclerosis score. Jacc Cardiovasc. Imaging 2014, 7, 366-373. [CrossRef] [PubMed]

13. Underhill, H.R.; Hatsukami, T.S.; Cai, J.; Yu, W.; DeMarco, J.K.; Polissar, N.L.; Ota, H.; Zhao, X.; Dong, L.; Oikawa, M.; et al. A noninvasive imaging approach to assess plaque severity: the carotid atherosclerosis score. Ajnr Am. J. Neuroradiol 2010, 31, 1068-1075. [CrossRef] [PubMed] 
14. Gupta, A.; Baradaran, H.; Schweitzer, A.D.; Kamel, H.; Pandya, A.; Delgado, D.; Dunning, A.; Mushlin, A.I.; Sanelli, P.C. Carotid plaque MRI and stroke risk: a systematic review and meta-analysis. Stroke 2013, 44, 3071-3077. [CrossRef]

15. Dong, L.; Kerwin, W.S.; Ferguson, M.S.; Li, R.; Wang, J.; Chen, H.; Canton, G.; Hatsukami, T.S.; Yuan, C. Cardiovascular magnetic resonance in carotid atherosclerotic disease. J. Cardiovasc. Magn. Reson. 2009, 11, 53. [CrossRef]

16. Mossa-Basha, M.; Wasserman, B.A. Low-Grade Carotid Stenosis: Implications of MR Imaging. Neuroimaging Clin. N Am. 2016, 26, 129-145. [CrossRef]

17. Freilinger, T.M.; Schindler, A.; Schmidt, C.; Grimm, J.; Cyran, C.; Schwarz, F.; Bamberg, F.; Linn, J.; Reiser, M.; Yuan, C.; et al. Prevalence of nonstenosing, complicated atherosclerotic plaques in cryptogenic stroke. Jacc Cardiovasc Imaging 2012, 5, 397-405. [CrossRef]

18. Gupta, A.; Gialdini, G.; Giambrone, A.E.; Lerario, M.P.; Baradaran, H.; Navi, B.B.; Marshall, R.S.; Iadecola, C.; Kamel, H. Association Between Nonstenosing Carotid Artery Plaque on MR Angiography and Acute Ischemic Stroke. Jacc Cardiovasc Imaging 2016, 9, 1228-1229. [CrossRef]

19. Saam, T.; Habs, M.; Buchholz, M.; Schindler, A.; Bayer-Karpinska, A.; Cyran, C.C.; Yuan, C.; Reiser, M.; Helck, A. Expansive arterial remodeling of the carotid arteries and its effect on atherosclerotic plaque composition and vulnerability: an in-vivo black-blood 3T CMR study in symptomatic stroke patients. J. Cardiovasc Magn. Reson. 2016, 18, 11. [CrossRef]

20. Kamel, H.; Merkler, A.E.; Iadecola, C.; Gupta, A.; Navi, B.B. Tailoring the Approach to Embolic Stroke of Undetermined Source: A Review. JAMA Neurol. 2019. [CrossRef]

21. Brinjikji, W.; Huston, J., 3rd; Rabinstein, A.A.; Kim, G.M.; Lerman, A.; Lanzino, G. Contemporary carotid imaging: from degree of stenosis to plaque vulnerability. J. Neurosurg. 2016, 124, 27-42. [CrossRef] [PubMed]

22. Zhao, X.; Li, R.; Hippe, D.S.; Hatsukami, T.S.; Yuan, C.; Investigators, C.-I. Chinese Atherosclerosis Risk Evaluation (CARE II) study: a novel cross-sectional, multicentre study of the prevalence of high-risk atherosclerotic carotid plaque in Chinese patients with ischaemic cerebrovascular events-design and rationale. Stroke Vasc. Neurol. 2017, 2, 15-20. [CrossRef]

23. Zhao, X.; Hippe, D.S.; Li, R.; Canton, G.M.; Sui, B.; Song, Y.; Li, F.; Xue, Y.; Sun, J.; Yamada, K.; et al. Prevalence and Characteristics of Carotid Artery High-Risk Atherosclerotic Plaques in Chinese Patients With Cerebrovascular Symptoms: A Chinese Atherosclerosis Risk Evaluation II Study. J. Am. Heart Assoc. 2017, 6. [CrossRef] [PubMed]

24. Kerwin, W.; Xu, D.; Liu, F.; Saam, T.; Underhill, H.; Takaya, N.; Chu, B.; Hatsukami, T.; Yuan, C. Magnetic resonance imaging of carotid atherosclerosis: plaque analysis. Top. Magn. Reson. Imaging 2007, 18, 371-378. [CrossRef] [PubMed]

25. Cai, J.M.; Hatsukami, T.S.; Ferguson, M.S.; Small, R.; Polissar, N.L.; Yuan, C. Classification of human carotid atherosclerotic lesions with in vivo multicontrast magnetic resonance imaging. Circulation 2002, 106, 1368-1373. [CrossRef] [PubMed]

26. Chu, B.; Kampschulte, A.; Ferguson, M.S.; Kerwin, W.S.; Yarnykh, V.L.; O’Brien, K.D.; Polissar, N.L.; Hatsukami, T.S.; Yuan, C. Hemorrhage in the atherosclerotic carotid plaque: a high-resolution MRI study. Stroke 2004, 35, 1079-1084. [CrossRef]

27. Li, F.; McDermott, M.M.; Li, D.; Carroll, T.J.; Hippe, D.S.; Kramer, C.M.; Fan, Z.; Zhao, X.; Hatsukami, T.S.; $\mathrm{Chu}, \mathrm{B}$; et al. The association of lesion eccentricity with plaque morphology and components in the superficial femoral artery: a high-spatial-resolution, multi-contrast weighted CMR study. J. Cardiovasc Magn. Reson. 2010, 12, 37. [CrossRef]

28. Ohara, T.; Toyoda, K.; Otsubo, R.; Nagatsuka, K.; Kubota, Y.; Yasaka, M.; Naritomi, H.; Minematsu, K. Eccentric stenosis of the carotid artery associated with ipsilateral cerebrovascular events. Ajnr Am. J. Neuroradiol. 2008, 29, 1200-1203. [CrossRef]

29. North American Symptomatic Carotid Endarterectomy Trial Collaborators; Barnett, H.J.M.; Taylor, D.W.; Haynes, R.B.; Sackett, D.L.; Peerless, S.J.; Ferguson, G.G.; Fox, A.J.; Rankin, R.N.; Hachinski, V.C.; et al. Beneficial effect of carotid endarterectomy in symptomatic patients with high-grade carotid stenosis. N. Engl. J. Med. 1991, 325, 445-453. [CrossRef]

30. Ota, H.; Reeves, M.J.; Zhu, D.C.; Majid, A.; Collar, A.; Yuan, C.; DeMarco, J.K. Sex differences in patients with asymptomatic carotid atherosclerotic plaque: in vivo 3.0-T magnetic resonance study. Stroke 2010, 41, 1630-1635. [CrossRef] 
31. Sangiorgi, G.; Roversi, S.; Biondi Zoccai, G.; Modena, M.G.; Servadei, F.; Ippoliti, A.; Mauriello, A. Sex-related differences in carotid plaque features and inflammation. J. Vasc. Surg. 2013, 57, 338-344. [CrossRef] [PubMed]

32. Kwee, R.M.; van Oostenbrugge, R.J.; Prins, M.H.; Ter Berg, J.W.; Franke, C.L.; Korten, A.G.; Meems, B.J.; van Engelshoven, J.M.; Wildberger, J.E.; Mess, W.H.; et al. Symptomatic patients with mild and moderate carotid stenosis: plaque features at MRI and association with cardiovascular risk factors and statin use. Stroke 2010, 41, 1389-1393. [CrossRef] [PubMed]

33. Cheung, H.M.; Moody, A.R.; Singh, N.; Bitar, R.; Zhan, J.; Leung, G. Late stage complicated atheroma in low-grade stenotic carotid disease: MR imaging depiction-prevalence and risk factors. Radiology 2011, 260, 841-847. [CrossRef] [PubMed]

34. Ota, H.; Reeves, M.J.; Zhu, D.C.; Majid, A.; Collar, A.; Yuan, C.; DeMarco, J.K. Sex differences of high-risk carotid atherosclerotic plaque with less than $50 \%$ stenosis in asymptomatic patients: an in vivo 3T MRI study. Ajnr Am. J. Neuroradiol 2013, 34, 1049-1055. [CrossRef]

35. Watase, H.; Sun, J.; Hippe, D.S.; Balu, N.; Li, F.; Zhao, X.; Mani, V.; Fayad, Z.A.; Fuster, V.; Hatsukami, T.S.; et al. Carotid Artery Remodeling Is Segment Specific: An In Vivo Study by Vessel Wall Magnetic Resonance Imaging. Arter. Thromb. Vasc. Biol. 2018, 38, 927-934. [CrossRef]

36. Terry, J.G.; Tang, R.; Espeland, M.A.; Davis, D.H.; Vieira, J.L.; Mercuri, M.F.; Crouse, J.R., 3rd. Carotid arterial structure in patients with documented coronary artery disease and disease-free control subjects. Circulation 2003, 107, 1146-1151. [CrossRef]

37. Bonithon-Kopp, C.; Touboul, P.J.; Berr, C.; Magne, C.; Ducimetiere, P. Factors of carotid arterial enlargement in a population aged 59 to 71 years: the EVA study. Stroke 1996, 27, 654-660. [CrossRef]

38. Chironi, G.; Gariepy, J.; Denarie, N.; Balice, M.; Megnien, J.L.; Levenson, J.; Simon, A. Influence of hypertension on early carotid artery remodeling. Arterioscler. Thromb. Vasc. Biol. 2003, 23, 1460-1464. [CrossRef]

39. Park, S.T.; Kim, J.K.; Yoon, K.H.; Park, S.O.; Park, S.W.; Kim, J.S.; Kim, S.J.; Suh, D.C. Atherosclerotic carotid stenoses of apical versus body lesions in high-risk carotid stenting patients. Ajnr Am. J. Neuroradiol 2010, 31, 1106-1112. [CrossRef]

40. Schulz, U.G.; Rothwell, P.M. Major variation in carotid bifurcation anatomy: a possible risk factor for plaque development? Stroke 2001, 32, 2522-2529. [CrossRef]

41. Phan, T.G.; Beare, R.J.; Jolley, D.; Das, G.; Ren, M.; Wong, K.; Chong, W.; Sinnott, M.D.; Hilton, J.E.; Srikanth, V. Carotid artery anatomy and geometry as risk factors for carotid atherosclerotic disease. Stroke 2012, 43, 1596-1601. [CrossRef] [PubMed]

42. Adams, H.P., Jr.; Bendixen, B.H.; Kappelle, L.J.; Biller, J.; Love, B.B.; Gordon, D.L.; Marsh, E.E., 3rd. Classification of subtype of acute ischemic stroke. Definitions for use in a multicenter clinical trial. TOAST. Trial of Org 10172 in Acute Stroke Treatment. Stroke 1993, 24, 35-41. [CrossRef] [PubMed]

43. Balu, N.; Yarnykh, V.L.; Chu, B.; Wang, J.; Hatsukami, T.; Yuan, C. Carotid plaque assessment using fast 3D isotropic resolution black-blood MRI. Magn. Reson. Med. 2011, 65, 627-637. [CrossRef] [PubMed]

44. Wang, J.; Bornert, P.; Zhao, H.; Hippe, D.S.; Zhao, X.; Balu, N.; Ferguson, M.S.; Hatsukami, T.S.; Xu, J.; Yuan, C.; et al. Simultaneous noncontrast angiography and intraplaque hemorrhage (SNAP) imaging for carotid atherosclerotic disease evaluation. Magn. Reson. Med. 2013, 69, 337-345. [CrossRef] [PubMed]

(C) 2019 by the authors. Licensee MDPI, Basel, Switzerland. This article is an open access article distributed under the terms and conditions of the Creative Commons Attribution (CC BY) license (http://creativecommons.org/licenses/by/4.0/). 